Open Access

\title{
Team rivalry and lending on crowdfunding platforms: an empirical analysis
}

\author{
Ling Ge and Xuechen Luo*
}

\author{
* Correspondence: \\ xuecheluo2-c@my.cityu.edu.hk \\ Department of Information Systems, \\ City University of Hong Kong, \\ Kowloon Tong, Hong Kong
}

\begin{abstract}
Background: Prosocial crowdfunding helps the underprivileged obtain non-profit seeking loans from multitudinous lenders. Some platforms introduce team competition to motivate member participation and may thus induce team rivalry.

Methods: We investigate how team rivalry affects lending decisions using data from Kiva.org. We argue that a rivalry relationship may engage teams to compete directly against rivals by lending to the same project or prevent them from doing so because they intend not to cooperate.

Result: We find that a team is less likely to lend to a project that has received funding from its rival team, suggesting that rival teams tend to avoid cooperation.

Conclusions: We discuss the implications of our findings for crowdfunding and competition-based motivation mechanisms in general.
\end{abstract}

Keywords: Crowdfunding, Prosocial lending, Rivalry relationship, Lending decision

\section{Background}

Crowdfunding brings lenders and borrowers together through internet platforms. It targets financial needs that are not profitable for traditional financial services, such as small businesses, social projects, or the poor. In particular, prosocial and donationbased crowdfunding platforms provide access to capital for poor and low-income populations from multitudinous funders internationally.

Prosocial lenders are motivated by ideals and altruism rather than monetary incentives (Burtch et al. 2013). It is thus imperative for platforms to keep lenders motivated to sustain contributions. Platforms often devise reputation-based mechanisms to engage participants to compete for recognition, such as scores, rankings, or badges based on their contribution. Interestingly, some platforms introduce team rivalry to leverage competition. For example, Kiva.org, the largest prosocial crowdfunding platform, allows lenders to build self-organized teams in accordance with their own interests, beliefs, geographic location, religion, and so on.

Team rivalry may affect lenders' lending behavior. The rivalry relationship may enhance teams' competitive intention and motivate them to contribute to loans (Kilduff et al. 2010). However, rivalry may also lead to reluctance to cooperate (Kogut 1989; Evald and Bager 2008). A team may potentially avoid a project that receives contributions from its rival team, even if the project is contribution worthy. The literature on online platforms contains few examples of this negative impact of rivalry.

(C) The Author(s). 2016 Open Access This article is distributed under the terms of the Creative Commons Attribution 4.0 International License (http://creativecommons.org/licenses/by/4.0/), which permits unrestricted use, distribution, and reproduction in any medium provided you give appropriate credit to the original author(s) and the source, provide a link to the Creative Commons license, and indicate if changes were made. 
Thus, the current study investigates how team rivalry affects lenders' choice of projects in the context of prosocial crowdfunding. We collected data from Kiva.org and show explorative results that the tendency of a lender to lend to a project decreases when a rival lends to the same project. The results suggest that lenders on rival teams avoid appearing cooperative.

We contribute to the literature on the role of social relationships in crowdfunding. Researchers have investigated the impact of social relationships on lending outcomes (Agrawal et al. 2015; Zheng et al. 2014; Mollick 2014; Burtch et al. 2013). Agrawal et al. (2015) suggested that although crowdfunding reduces distance-related frictions, the offline social relationship of borrowers is still a very significant factor that affects funders' contribution patterns. Zheng et al. (2014) found that the social relationship of entrepreneurs positively and significantly affects their crowdfunding performance and the effect is more significant in the Chinese market. Mollick (2014) demonstrated that the number of Facebook friends shown on crowdfunding platforms helps to predict the success of funding. Lin et al. (2013) found that friends of a borrower can serve as a signal of credit quality for peer-to-peer lending. Borrowers with friends are more likely to obtain funding with a lower interest rate and they default less. Liu et al. (2015) differentiated the signaling mechanisms of friendship as pipe, prism, and herding. Closer friends of borrowers are more likely to help (pipe), endorsement of friends may dilute a third party's lending (prism), and lenders are likely to follow their friends (herding). Our study of the rivalry relationship on lending behavior enriches the understanding of social relationships on online platforms.

The rest of the paper is organized as follows. The next section introduces the research context before the literature and hypotheses development. The subsequent section describes the empirical strategies and analysis. We conclude the paper with a discussion of implications and future research directions.

\section{Research context}

Launched in 2005, Kiva.org currently covers borrowers from more than 80 countries, thus providing a rich context for our study. Kiva aims to provide loans for projects to alleviate poverty with interest-free loans from worldwide lenders.

Lenders can organize teams on Kiva based on any attribute, such as interest, location, religion, or university. For example, a team named "Guys holding fish" claims: "We feel an affinity for entrepreneurs that make their living by fishing, selling fish, or attempting to make their lives better because of their proximity to the ocean, or freshwater locales..." Some teams may form a rivalry if they advocate opposing beliefs or identities, such as rival universities, competing companies, or contrary beliefs. For example, some teams include "Kiva Christian," "LGBT Kivans \& Friends," "Team Canada," and "Team MIT," among others. Team rivalry arises according to what teams identify with: nations that compete historically, such as England and France; universities that compete for students, job markets, or in sports, such as Harvard and MIT; and ideological groups that hold contrasting views, such as conservative Christians and LGBT groups. Lenders can join any team and attribute their contributions to the team. Therefore, rival teams could compete for reputation based on team-level contributions.

Teams may compete for recognition or visibility. Any lender can join teams they are interested in and attribute their contribution to any of their teams. Kiva ranks teams' 
contributions in terms of loan amounts and new members. Figure 1 shows the team page on Kiva. It includes a team list ranked by total amount, number, and member loans in addition to team leaderboards that present monthly rankings based on loan amounts or number of new members. The two teams that have lent the most overall are "Kiva Lending Team: (A+) Atheists, Agnostics, Skeptics, Freethinkers, Secular Humanists and the Non-Religious" and "Kiva Christians." The rivalry between the two teams seems salient.

The loan's homepage shows team contributions to each loan. As shown in Fig. 2, the page displays the list of lenders and the lender's team. Teams are listed based on the sequence of their contributions. We are interested in determining whether a member who observes a rival team contributes to a project could compete against the rival by lending to the same project or show no intention of cooperating by avoiding the project. Next, we develop our theoretical arguments to answer the question.

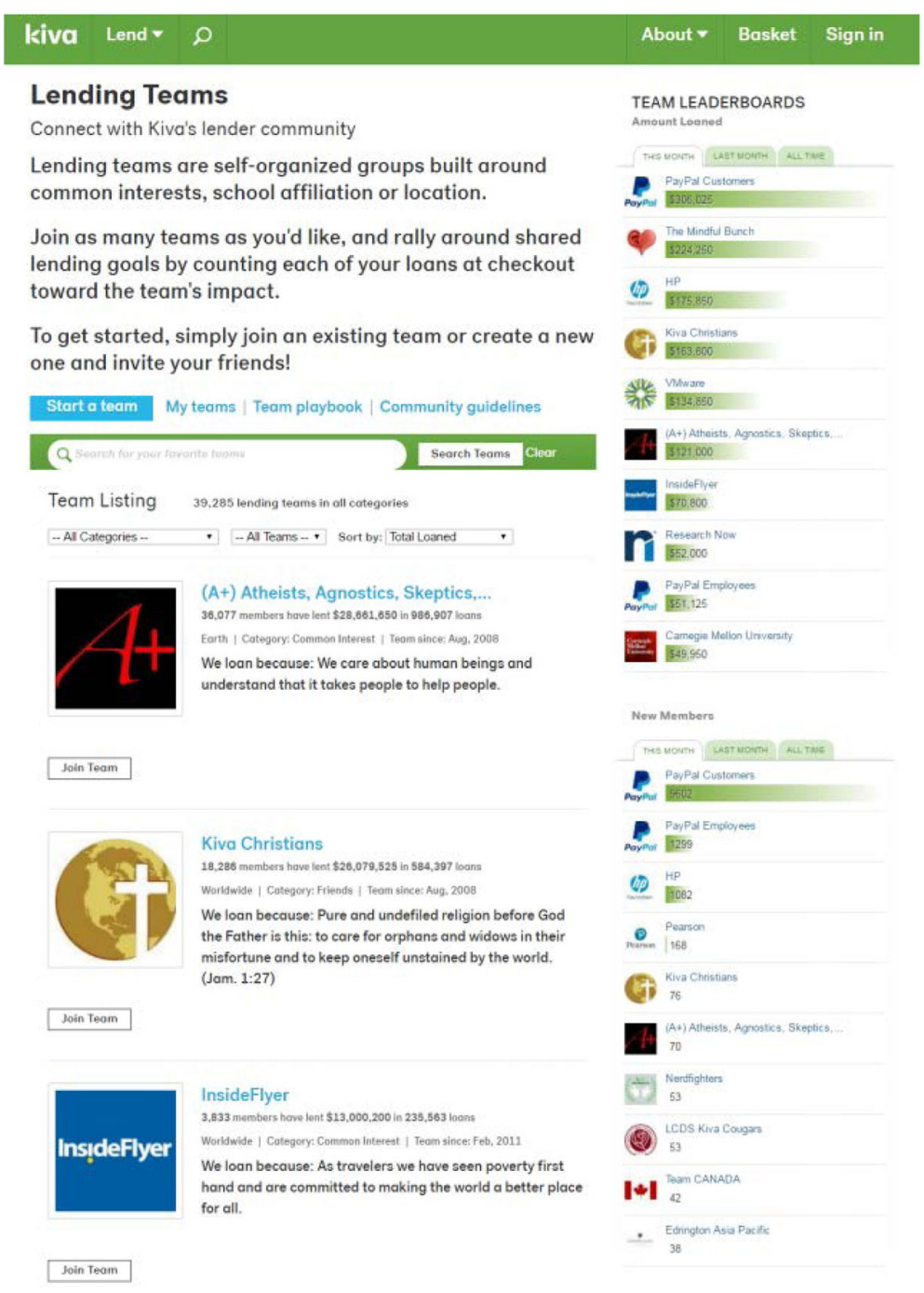

Fig. 1 The team page 


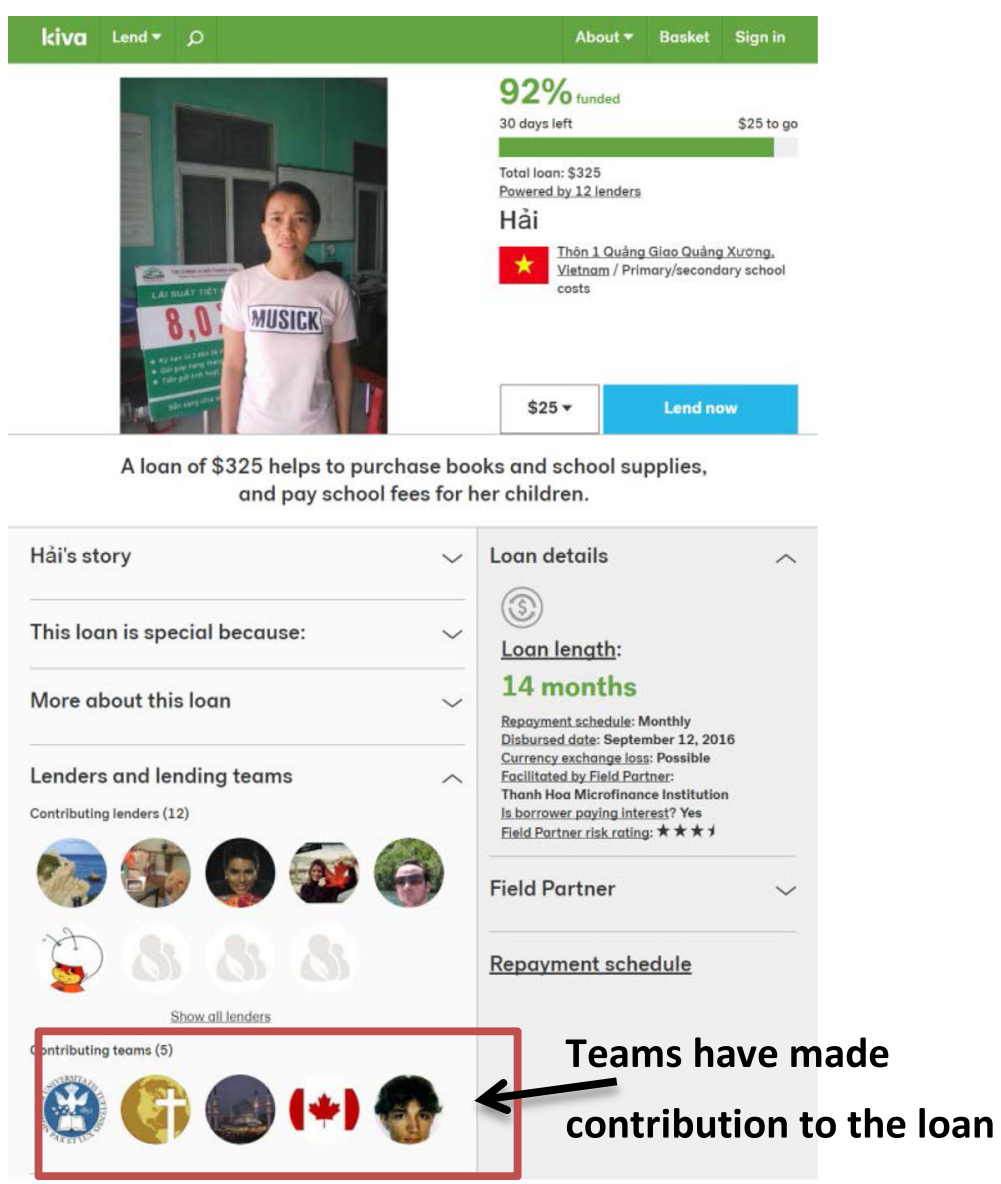

Fig. 2 Loan portfolio page

\section{Theoretical background}

How rivalry affects competition or cooperation has long been discussed in the literature. Some researchers confirmed that rivalry can motivate people to compete for better performance (e.g., Erev et al. 1993; Young et al. 1996; Brown et al. 1998). However, some studies found that rivalry-induced competition works no better than cooperation and may reduce motivation and productivity (e.g., Lawless and Anderson 1996; Stanne et al. 1999). To resolve these inconsistent findings, some researchers suggested that the impact of rivalry might depend on the nature of the task. For instance, if rival teams' tasks affect the performance of the opposing team, rivalry leads to less desirable results (Tauer and Harackiewicz 2004). Rivalry decreases intentions to cooperate and leads to lower cooperation performance (Kogut 1989; Evald and Bager 2008).

Kiva team members may be motivated to compete against their rivals. The platform makes contribution behavior transparent on both the loans and team pages. Members observing the rival team's performance feel competitive and act upon it (Kilduff et al. 2010). At the team level, the pressure from rivalry may even reduce individual members' incentive to free ride (Erev et al. 1993). Thus, a team's contribution to a project may have a positive effect on its rival team's probability to lend subsequently to the same project.

Interestingly, contributing to the same project indicates cooperation. On crowdfunding, the project does not receive funding until the contribution reaches the target 
amount. Thus, a project's success depends on multitudinous lenders who voluntarily contributing together. If the project could not be fully funded, current contributions will be refunded and do not count toward team performance. A team member may consider lending to a project that the rival team has already lent to as cooperating with the rival team to achieve its goals. Members may then be reluctant to cooperate with a rival team (Kogut 1989; Evald and Bager 2008). Furthermore, as lenders more likely to contribute to borrowers with a shorter culture distance and close social resemblance to themselves (Burtch et al. 2014; Galak et al. 2011), members may infer from a rival team contribution that the project may not be a good match for their own team. Thus, we would expect that a team is less likely to contribute to a project that has received a contribution from its rival team.

Therefore, a rivalry relationship may either initiate direct competition or discourage others from contributing to a project. In the following section, we present our empirical analysis of Kiva data and identify the impact of rivalry.

\section{Methods}

Data

We obtained weekly data from 10/21/2015 to 4/12/2015, covering 8 weeks of activities on Kiva. In this explorative study, we picked two pairs of rival teams: the first pair consisting of "Kiva Christians" and "LGBT Kivan \& Friends," and the second consisting of "Team Canada" and "Team Australia." In the former case, Kiva Christians hold conservative positions against LGBT groups, and these teams often appear on the leaderboard with similar levels of contributions. In the latter case, these countries have been documented as having a sibling rivalry (MacMillan 2003).

For the 8 week sample period, there were 23,336 listed projects. For each project, we derived a list of all contributing teams in the chronological order of their contributions. Using "LGBT Kivan \& Friends" and "Team Canada" as focal teams, we record whether they contribute to each project as our dependent variable. We then search through the team list to identify whether the rival teams "Kiva Christian" or "Australia," respectively, contributed before the focal teams. The final cross-sectional data contains information about each project and rival teams' contributions.

\section{Main model}

We estimate how a team's contribution to a project affects the probability of its rival team making a subsequent contribution to the same project with the following model:

$$
\text { LendingDecision }_{\text {in }}=\beta_{0}+\beta_{1} \text { RivalryLending }_{\text {jn }}+\beta_{2} \text { ControlVar }_{n}+\varepsilon_{\text {in }}
$$

where $i$ represents the focal team, $j$ represents the rival team, and $n$ refers to project $n$. The dependent variable, LendingDecision ${ }_{i n}$, is a binary variable indicating whether team

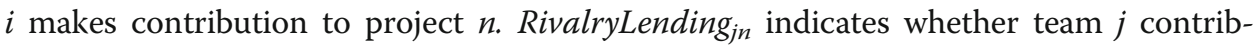
uted to the project before team $i$, which we can determine by scanning the team list on the project page. ControlVar ${ }_{n}$ includes the characteristics of the project that may affect the team's lending decision, such as whether the original language of project description is English, whether it is group borrowing, the amount requested, and the category. 


\section{Results}

Table 1 shows the results of the model estimation. Both Model 1 and 2 demonstrate the negative and significant impact of rival lending on the focal team's subsequent lending. This means that the probability of a team lending to a project decreases if its rival has lent to this project. The results confirm that teams tend not to cooperate through rivalry by avoiding contributing to the same project.

\section{Falsification checks}

It could be argued that the analysis is picking up spurious rivalry effect as a result of coincidence. To establish the causality further, we perform a falsification check using non-rival team contributions instead of rival teams as the independent variable. Specifically, we choose "Team Belgium" to pair with the LGBT team since Belgium is one of the most LGBT-friendly countries. Similarly, we pair team "Canada" with team "US" and "New York" as non-rivals.

The results in Table 2 show that non-rival lending has no significant impact on a team's tendency to lend to a project. Therefore, the evidence suggests that the effect of rival lending is not coincidental.

\section{Discussion and conclusion}

We investigate how a rivalry relationship affects funding decisions at the team level in the context of prosocial crowdfunding. We argue that a rivalry relationship may engage teams to compete directly against rivals by lending to the same project or prevent them from doing so because they intend not to cooperate. With data from Kiva, our empirical analysis confirms the latter case: rival teams would be reluctant to contribute to the same project. The study has theoretical and practical implications for crowdfunding.

This might be one of the first study to explore the role of a rivalry relationship in crowdfunding. Most extant literature focuses on link-based social relationships such as friendship (e.g., Lin et al. 2013; Liu et al. 2015). Our findings of a negative impact of

Table 1 Impact of rival lending on team lending decisions

\begin{tabular}{lll}
\hline $\begin{array}{l}\text { Dependent } \\
\text { variable }\end{array}$ & Lending decision & Lending decision \\
\hline Rival Lending & $-0.6602^{* * *}$ & Canada vs. Australia \\
English or Not & $(0.0585)$ & $-0.1304^{* *}$ \\
& $0.1058^{*}$ & $(0.0611)$ \\
Group Loan or not & $(0.0540)$ & 0.0114 \\
& $0.6236^{* * *}$ & $(0.0421)$ \\
Ln (Loan Amount) & $(0.0692)$ & $0.1807^{* * *}$ \\
& $0.9574^{* * *}$ & $(0.0566)$ \\
Constant & $(0.0376)$ & 0.8506 \\
Category Controls & $-8.6215^{* * *}$ & $(0.0280)$ \\
Observations & $(0.2618)$ & $-7.2934^{* * *}$ \\
\hline
\end{tabular}

${ }^{* * *} p<0.001,{ }^{* *} p<0.01,{ }^{*} p<0.05$, standard error in parentheses 
Table 2 Falsification test using non-rivalry teams

\begin{tabular}{lll}
\hline $\begin{array}{l}\text { Dependent } \\
\text { variable }\end{array}$ & $\begin{array}{l}\text { Lending decision } \\
\text { LGBT vs. Belgium }\end{array}$ & Lending decision \\
\hline Non-Rival Lending & -0.1103 & -0.1902 \\
English or Not & $(0.0723)$ & $(0.1639)$ \\
Group Loan or not & 0.0916 & $0.4198^{* * *}$ \\
& $(0.0563$ & $(0.0787)$ \\
Ln (Loan Amount) & $0.5680^{* * *}$ & 0.1633 \\
& $(0.0691)$ & $(0.0997)$ \\
Constant & $0.8508^{* * *}$ & $0.5433^{* * *}$ \\
Industry Controls & $(0.0365)$ & $(0.0482)$ \\
Observations & $-8.1040^{* * *}$ & $-7.0747^{* * *}$ \\
\hline
\end{tabular}

*** $p<0.001,{ }^{* *} p<0.01,{ }^{*} p<0.05$, standard error in parentheses

rivalry relationship confirm the significance of rivalry relationship on funding choices. It warrants further research to improve our understanding and to build a theory of this type of social relationship. Furthermore, many online communities that rely on participants' voluntary contribution usually use competition for reputation as a motivating mechanism. Rivalry relationship can originate not only from competition, but also from offline social aspects. Thus, our research has implications for more general online communities.

Our study also provides insights for crowdfunding platforms to design motivational mechanisms. Platforms introduce teams to create a sense of competition and thus motivate members to contribute. Our findings demonstrate that rivalry-based competition may cause inefficiencies in funding choices. Rivalry may encourage members to forego a fundable project or contribute to a project they would not want to otherwise. Therefore, crowdfunding platforms need to be cautious in using rivalry as motivational mechanism, such as by considering whether to disclose team contribution information or when to disclose the information.

We acknowledge several limitations of the study. First, our study is an explorative study of rivalry relationship. Further work needs to be done to gain full understanding of the role of rivalry relationship. For instance, we should also examine the impact of rivalry on teams' overall funding performance. Second, this study conducts an analysis at the team level. Understanding the observed negative impact will require an analysis at the individual member level.

Funding

This research is supported by the startup fund from City University of Hong Kong.

Authors' contributions

Both authors contributed equally. Both authors read and approved the final manuscript.

Competing interests

The authors declare that they have no competing interests. 
References

Agrawal A, Catalini C, Goldfarb A (2015) Crowdfunding: geography, social networks, and the timing of investment decisions. J Econ Manag Strateg 24(2):253-274

Brown SP, Cron WL, Slocum JW, Jr (1998) Effects of trait competitiveness and perceived intraorganizational competition on salesperson goal setting and performance. J Mark 62:88-98.

Burtch G, Ghose A, Wattal S (2013) An empirical examination of the antecedents and consequences of contribution patterns in crowd-funded markets. Inf Syst Res 24(3):499-519

Burtch G, Ghose A, Wattal S (2014) Cultural differences and geography as determinants of online prosocial lending. MIS Q 38(3): 773-794

Erev I, Bornstein G, Galili R (1993) Constructive intergroup competition as a solution to the free rider problem: a field experiment. J Exp Soc Psychol 29(6):463-478

Evald MR, Bager T (2008) Managing venture team relationships in corporate incubators: a case study of network dynamics and political rivalry in a high-tech incubator. Int Entrep Manag J 4(3):349-364

Galak J, Small D, Stephen AT (2011) Microfinance decision making: a field study of prosocial lending. J Mark Res 48(SPL):S130-S137

Kilduff GJ, Elfenbein HA, Staw BM (2010) The psychology of rivalry: a relationally dependent analysis of competition. Acad Manag J 53(5):943-969

Kogut B (1989) The stability of joint ventures: reciprocity and competitive rivalry. J Ind Econ 38:183-198

Lawless MW, Anderson PC (1996) Generational technological change: effects of innovation and local rivalry on performance. Acad Manag J 39(5):1185-1217

Lin M, Prabhala NR, Viswanathan S (2013) Judging borrowers by the company they keep: friendship networks and information asymmetry in online peer-to-peer lending. Manag Sci 59(1):17-35

Liu D, Brass D, Lu Y, Chen D (2015) Friendships in online peer-to-peer lending: pipes, prisms, and relational herding MIS Q 39(3):729-742

MacMillan M (2003). Parties long estranged: Canada and Australia in the twentieth century. Vancouver: UBC Press. Mollick E (2014) The dynamics of crowdfunding: an exploratory study. J Bus Ventur 29(1):1-16, [9] O.M. Lehner, A literature

Stanne MB, Johnson DW, Johnson RT (1999) Does competition enhance or inhibit motor performance: a meta-analysis. Psychol Bull 125(1):133

Tauer JM, Harackiewicz JM (2004) The effects of cooperation and competition on intrinsic motivation and performance. J Pers Soc Psychol 86(6):849

Young G, Smith KG, Grimm CM (1996) "Austrian" and industrial organization perspectives on firm-level competitive activity and performance. Organ Sci 7(3):243-254

Zheng H, Li D, Wu J, Xu Y (2014) The role of multidimensional social capital in crowdfunding: a comparative study in China and US. Inf Manag 51(4):488-496

\section{Submit your manuscript to a SpringerOpen ${ }^{\circ}$ journal and benefit from:}

- Convenient online submission

- Rigorous peer review

- Immediate publication on acceptance

- Open access: articles freely available online

- High visibility within the field

- Retaining the copyright to your article

Submit your next manuscript at $>$ springeropen.com 